\title{
əUtilizing Recent Climate Data in Eastern Texas to Calculate Trends in Measures of Aridity and Estimate Changes in Watering Demand for Landscape Preservation
}

\author{
ROBERT KENNEDY SMITH \\ Department of Mathematics and Statistics, Georgetown University, Washington, D.C. \\ DER-CHEN CHANG \\ Department of Mathematics and Statistics, Georgetown University, Washington, D.C., and Graduate Institution of Business \\ Administration, College of Management, Fu Jen Catholic University, New Taipei City, Taiwan
}

(Manuscript received 9 August 2019, in final form 28 October 2019)

\begin{abstract}
Eastern Texas houses a transition zone from semiarid conditions in the far west to some of the wettest areas of the continental United States not influenced by mountainous terrain. The region, vulnerable to drought and flooding rains, is projected to experience higher water demand with its growing population. In the coming decades, municipal consumption, including water for landscape preservation, will supplant irrigation as the largest usage category. The amount of supplemental water required to maintain plantings is dependent on evapotranspirative demand and precipitation patterns. Reference evapotranspiration can be calculated using four daily climate parameters in the FAO-56 Penman-Monteith equation. This was combined with soil moisture capacity and daily accumulated precipitation to determine historical evapotranspiration rates at 14 observation stations across the eastern region of Texas from 1973 through 2017 and allowed for the creation of a recursive algorithm that introduced supplemental water for vegetation preservation as conditions crossed thresholds of dryness. Time series data analysis showed an increasing degree of aridity, as higher temperatures have decreased relative humidity and dry periods have become more prolonged and severe under stable average annual precipitation totals. Without additional increases in rainfall, the region is expected to continue its drying trend, leading to moisture-stressed plant life and higher water demands to maintain landscapes in a well-watered state.
\end{abstract}

\section{Introduction}

From late 2010 to late 2011, the state of Texas experienced an unprecedented 1-yr drought. The Drought Monitor, a collaborative effort between U.S. government agencies and the University of Nebraska-Lincoln, uses five drought classifications [from abnormally dry conditions (D0) to exceptional drought (D4)] to describe parched landscapes (Svoboda et al. 2002). During the spring of $2011,100 \%$ of the state was experiencing some type of drought; by the summer of that year, $72 \%$ of Texas was under an exceptional drought (NielsonGammon 2012). Fueled by a combination of abnormally high temperatures, low relative humidity, and lack of

¿ Denotes content that is immediately available upon publication as open access.

Corresponding author: Robert Kennedy Smith, rks2@georgetown.edu precipitation, the drought caused billions of dollars in damage and spurred the passage of new legislation to improve water-related infrastructure (Nielson-Gammon 2012; Henry 2013). Voters approved the package, creating the State Water Implementation Fund (SWIFT) and the State Water Implementation Revenue Fund for Texas (SWIRFT), assisting regions with drought mitigation plan development (Texas Water Development Board 2017). Several years later, rain from Hurricane Harvey led the city of Houston, Texas, to its wettest calendar year on record, as over 3 times as much precipitation fell in Houston during 2017 as in 2011 (National Weather Service 2019). The role of climate change from anthropogenic greenhouse gas emissions has been discussed in these and other events (AghaKouchak et al. 2013; Long et al. 2013), leading to questions about the sustainability of the Texas water supply in coming decades as extreme events are projected to continue and increase in severity. 
TABLE 1. Locations of the 14 observation stations (from west to east).

\begin{tabular}{|c|c|c|c|c|c|}
\hline $\begin{array}{l}\text { Station } \\
\text { identifier }\end{array}$ & Station name & Lat & Lon & Elev & $\begin{array}{l}\text { Annual avg precipitation } \\
\text { (1973-2017) }\end{array}$ \\
\hline 1 & Wichita Falls Municipal Airport, TX & $33.98^{\circ} \mathrm{N}$ & $98.49^{\circ} \mathrm{W}$ & $310.0 \mathrm{~m}$ & $723 \mathrm{~mm}$ \\
\hline 2 & San Antonio International Airport, TX & $29.54^{\circ} \mathrm{N}$ & $98.48^{\circ} \mathrm{W}$ & $240.5 \mathrm{~m}$ & $836 \mathrm{~mm}$ \\
\hline 3 & McAllen International Airport, TX & $26.18^{\circ} \mathrm{N}$ & $98.25^{\circ} \mathrm{W}$ & $30.5 \mathrm{~m}$ & $563 \mathrm{~mm}$ \\
\hline 4 & Mathis 4 SSW, TX & $28.04^{\circ} \mathrm{N}$ & $97.87^{\circ} \mathrm{W}$ & $42.1 \mathrm{~m}$ & $748 \mathrm{~mm}$ \\
\hline 5 & $\begin{array}{l}\text { Brownsville South Padre Island International } \\
\text { Airport, TX }\end{array}$ & $25.91^{\circ} \mathrm{N}$ & $97.42^{\circ} \mathrm{W}$ & $7.3 \mathrm{~m}$ & $695 \mathrm{~mm}$ \\
\hline 6 & Waco Regional Airport, TX & $31.62^{\circ} \mathrm{N}$ & $97.23^{\circ} \mathrm{W}$ & $152.4 \mathrm{~m}$ & $885 \mathrm{~mm}$ \\
\hline 7 & Dallas/Fort Worth International Airport, TX & $32.90^{\circ} \mathrm{N}$ & $97.02^{\circ} \mathrm{W}$ & $170.7 \mathrm{~m}$ & $896 \mathrm{~mm}$ \\
\hline 8 & Victoria Regional Airport, TX & $28.84^{\circ} \mathrm{N}$ & $96.92^{\circ} \mathrm{W}$ & $31.7 \mathrm{~m}$ & $1019 \mathrm{~mm}$ \\
\hline 9 & Palacios Municipal Airport, TX & $28.72^{\circ} \mathrm{N}$ & $96.25^{\circ} \mathrm{W}$ & $3.7 \mathrm{~m}$ & $1120 \mathrm{~mm}$ \\
\hline 10 & George Bush Intercontinental Airport, TX & $29.98^{\circ} \mathrm{N}$ & $95.36^{\circ} \mathrm{W}$ & $29.0 \mathrm{~m}$ & $1273 \mathrm{~mm}$ \\
\hline 11 & William P. Hobby Airport, TX & $29.64^{\circ} \mathrm{N}$ & $95.28^{\circ} \mathrm{W}$ & $13.4 \mathrm{~m}$ & $1392 \mathrm{~mm}$ \\
\hline 12 & Angelina County Airport, TX & $31.24^{\circ} \mathrm{N}$ & $94.75^{\circ} \mathrm{W}$ & $87.8 \mathrm{~m}$ & $1217 \mathrm{~mm}$ \\
\hline 13 & Jack Brooks Regional Airport, TX & $29.95^{\circ} \mathrm{N}$ & $94.02^{\circ} \mathrm{W}$ & $4.9 \mathrm{~m}$ & $1541 \mathrm{~mm}$ \\
\hline 14 & Shreveport Regional Airport, LA & $32.45^{\circ} \mathrm{N}$ & $93.82^{\circ} \mathrm{W}$ & $77.4 \mathrm{~m}$ & $1276 \mathrm{~mm}$ \\
\hline
\end{tabular}

To ascertain how these recent events fit into multidecadal trends that can impact landscaping water demand in the region of eastern Texas (Table 1), daily climate data from 14 locations in the region from 1973 through 2017 were used in the development of a recursive algorithm that quantified the amount of supplemental water required to maintain vegetation in a consistently well-watered state. Time series data analysis was conducted on the accumulated water demand, comparing average expected amounts at the beginning and end of the analysis period. A discussion of trends exhibited by the parameters used in the algorithm provides the reader with context and evidence supporting the conclusions.

\section{Background}

The Texas Water Development Board, a state government agency, was established at the conclusion of the 1950s drought. The board makes projections of water usage and supply, anticipating a $17 \%$ increase in water demand in the next 50 years, from 22.7 billion $\mathrm{m}^{3}$ today to 26.6 billion $\mathrm{m}^{3}$ in 2070 . Municipal water usage, which includes potable water used on landscaping and is driven by an anticipated $70 \%$ growth in the state's population, is projected to increase by $62 \%$ over the same time period, surpassing irrigation as the largest usage category in Texas (Texas Water Development Board 2017). The board notes that if new supplies are not developed and conservation measures are not implemented, one-third of the Texas population will have less than one-half of its municipal demand met by 2070 . By that year, municipal water shortages would be 6 times as severe as those today and aggregate economic losses for the state would be $\$ 151$ billion (Texas Water Development Board 2017).
Water demand and availability projections during periods of scarcity by the Texas Water Development Board are based on the 1950s drought, the severe longterm event in Texas, and do not explicitly account for extreme events influenced by rising temperatures (McGregor 2015). Yet, the impacts of climate change may affect the duration, severity, and frequency of future drought and heavy precipitation events.

The eastern half of Texas receives significant annual precipitation from deep-convective storm systems and individual thunderstorm cells that may occur between prolonged dry spells (Fritsch et al. 1986). Average annual precipitation in the region increases from west to east. Coastal areas in the region are influenced by tropical systems and have higher relative humidity values, but there is not a noticeable annual precipitation gradient based on latitude (Schmandt et al. 2011). The high degree of interannual precipitation variability in the eastern half of Texas is influenced by sea surface temperatures in the Pacific Ocean. El Niño-Southern Oscillation (ENSO) cycles lead to wet winters in the southern United States when equatorial Pacific waters are warmer than average and dry winters when equatorial waters are abnormally cool. The 2010-11 Texas drought began with La Niña conditions developing during the autumn of 2010 , although the drought persisted through the summer of 2011 as a result of mean flow circulation anomalies and low soil moisture levels (Seager et al. 2014). Some studies indicate that higher global temperatures will lead to more frequent El Niño events, raising seasonal precipitation totals (Wang et al. 2017).

Average annual temperatures over the contiguous United States have increased by $0.7^{\circ} \mathrm{C}$ over the last few decades and will continue to rise (Hayhoe et al. 2018). National and regional studies have also concluded that the frequency and intensity of heavy precipitation 
events have increased at a greater rate than overall precipitation, partially caused by higher levels of atmospheric water vapor from increased evaporation (Hayhoe et al. 2018; Ryu and Hayhoe 2017). Model results show that eastern Texas lies between areas to the northeast that are projected to have higher annual precipitation totals and areas to the southwest for which lower totals are expected (Prein et al. 2016).

In recent decades, higher reference evapotranspiration rates have been experienced across the southern plains, an area that includes eastern Texas (Ficklin et al. 2015; Kramer et al. 2015). Increased variability in summer rainfall has also impacted areas to the east, prolonging and deepening dry periods (Wang et al. 2010). One study showed that some areas east of the 100th meridian (the westernmost observation site included in this analysis is located at $98.5^{\circ} \mathrm{W}$ ) can now be classified as arid when considering the U.S. arid-humid transition zone (Seager et al. 2018). This is in agreement with other models and analyses projecting persistent droughts interspersed with wet periods over the continental United States that are longer, cover more area, and are more intense (Lall et al. 2018). Chapter 23 of the Fourth National Climate Assessment, Volume II, summarizes the impact of these predictions on the southern plains, "The expected increase of precipitation intensity implies fewer soaking rains and more time to dry out between events, with an attendant increase in soil moisture stress" (Kloesel et al. 2018).

While many areas in eastern Texas have had wetter years relative to the baseline period in the first half of the twentieth century, most of this increase is from additional rain in the autumn (Easterling et al. 2017). Even if annual periods become wetter on average, drier spring and summer months can introduce additional stress for plant life and water supply systems. Moreover, other human influences can create microclimates that are not detected in global climate models. The expanding urban island heat effect in metropolitan Houston has caused summertime rainfall amounts to increase, because of a higher temperature difference between dry land and the Gulf of Mexico during the late afternoon (Burian and Shepherd 2005).

\section{Method}

The structure of the recursive supplemental water algorithm, a tool that estimates the amount of additional moisture needed to mitigate drought-induced stress on planted landscapes, is introduced later in the section. The analyzed time series data from its output are presented in the results and discussion section, along with analyses of the input parameters. In the first part of this section, background is given on the scope and management of the climate data used in the algorithm's development, before a description of its method is presented.

Daily soil moisture levels were calculated from the FAO-56 Penman-Monteith equation. The equation uses four climatic parameters averaged over each day - wind speed $\left(\mathrm{m} \mathrm{s}^{-1}\right)$, solar radiation $\left[\mathrm{MJ} \mathrm{m}^{-2} \mathrm{day}^{-1}\right]$, air temperature $\left({ }^{\circ} \mathrm{C}\right)$, and dewpoint temperature $\left({ }^{\circ} \mathrm{C}\right)$ - to calculate evapotranspiration rates on a grassy surface (Zontarelli et al. 2010). On days when large amounts of precipitation fall, moisture lost through evapotranspiration is replenished, raising soil water content. Each of the 14 observation stations was chosen on the basis of location, providing coverage across the eastern region of Texas, and the absence of large numbers of incomplete or missing records. For any station with incomplete parameters, data were supplemented from the closest observation station that had a complete record for the day in question.

Apart from average daily solar radiation values, all climate parameters originated from publicly available records (https://data.noaa.gov/dataset/d ataset/globalsurface-summary-of-the-day-gsod; https://www.ncdc. noaa.gov/data-access/land-based-station-data/land-baseddatasets/global-historical-climatology-network-ghon) at the National Centers for Environmental Information (NCEI), part of the U.S. government's National Oceanic and Atmospheric Administration. Solar data originated from the Climate Engine Organization, a partnership of the Desert Research Institute, the University of Idaho, and Google (http://climateengine.org/) and was created as part of the North American Regional Reanalysis (NARR), an extension of the NCEP Global Reanalysis. NARR data are only available from 1979, so linear regressions were run using the NCEI parameters as predictor variables to calculate radiation values for the first six years of the period. A separate regression was completed for each month at each site since climatological patterns can change the impact of parameters. For example, a low high temperature reading during the summer months is almost always indicative of cloudy skies, yet sunny winter days often occur during cold snaps. In addition to average daily temperature, the difference between each day's high and low recorded temperature was included as a predictor variable. $R$-squared values for the regressions were usually above 0.50 , providing confidence in the ability of the parameters to predict average solar radiation. A small caveat exists since the period of 1973-78 contained some of the wettest years on record for many sites: the linear regressions in which the daily precipitation amount carried a statistically significant negative coefficient likely overstated the impact of rainy days on solar radiation and caused abnormally low values. 
Reference evapotranspiration $\left(\mathrm{ET}_{0}\right)$ rates $(\mathrm{mm})$ estimated by the Penman-Monteith equation assume unlimited water availability, negating the consideration of the moisture-holding capacity of different soils. The vegetation surface covering used is the most common standard: a uniform crop of well-watered, clipped, cool-season grass, such as fescue, at a height of $0.12 \mathrm{~m}$, completely shading the ground, with a fixed surface resistance and albedo characteristics that approximate a standard residential lawn (Wright 1993). Alternatively, $\mathrm{ET}_{0}$ rates can be estimated with a 0.5 -m-high alfalfa crop, however clipped grass better approximates watered surfaces in residential and commercial areas. An adjustment is needed for $\mathrm{ET}_{0}$ values during periods of winter dormancy, when grass browns and is unable to grow. A dormancyadjustment crop multiplier, $K_{c}=0.2$, is used for reference evapotranspiration rates on days when the average temperature remains below $4.5^{\circ} \mathrm{C}$ (Jensen and Allen 2016). This value is modeled on the basis of findings from studies of evapotranspiration rates from silage remaining on the field after a final autumn harvest. Such days are infrequent in eastern Texas and occur during months in which $\mathrm{ET}_{0}$ values are at their annual minima.

While optimal growing conditions under $\mathrm{ET}_{0}$ assumptions assume no water scarcity, real-world conditions require soil moisture deficit calculations and the known water-holding capacity of the soils at each observation site for watering demand calculations (Wright 1993). Information on each location's soil was obtained from the USDA National Resources Conservation Service's online soil survey (https:// websoilsurvey.sc.egov.usda.gov/App/WebSoilSurvey. aspx). A weighted average of soils over a 4000-ha plot surrounding each observation site produced estimated total available water (TAW), defined as the field capacity of the soil minus its wilting point. The moisture content at field capacity is the amount of water $(\mathrm{mm})$ that can be held when the soil is saturated, and the wilting point is defined as the amount of water $(\mathrm{mm})$ in the soil when it can no longer provide any moisture to a plant for maintaining turgidity.

For the reference grassy surface, roots were assumed to penetrate the soil to a depth of $1 \mathrm{~m}$ and could draw up to $40 \%$ of TAW before being impacted by moisture deficiencies (Wright 1993). Thus, each soil's readily available water content (RAW) is TAW multiplied by a coefficient of 0.4. Without precipitation, the accumulated soil moisture depletion (ASMD) exceeds RAW and the grass begins to show signs of stress. An additional adjustment factor $K_{s}$ diminishes the stressed vegetation's evapotranspiration rates during conditions of limited moisture. At the point of initial stress, $K_{s}$ declines from a value of 1 . If no water enters the ground, $K_{s}$ reaches its minimum value of 0 when the soil's TAW is depleted. Many plants will die or suffer irreparable damage at $K_{s}$ levels below 0.2 (Ferguson 1987). The preceding discussion does not account for the variety of vegetation and root systems that exist in these areas, a soil's ability to provide limited moisture beyond its wilting point, and additional moisture losses from cracking. The calculation of $K_{s, t}$ (the value of $K_{s}$ during day $t$ ) is given by

$$
\begin{aligned}
K_{s, t}= & \frac{\mathrm{TAW}_{t}-\mathrm{ASMD}_{t-1}}{(1-0.4)\left(\mathrm{TAW}_{t}\right)} \text { for all } \mathrm{ASMD}_{t-1}>\mathrm{RAW}_{t-1} \\
& (t-1 \text { is the previous day }) .
\end{aligned}
$$

When precipitation fell on unsaturated soils that were not at their field capacity water-holding levels, the entire amount of water received, in $\mathrm{mm}$, was assumed to be absorbed into the ground and retained. Once RAW reached its maximum value, water introduced to soil at field capacity would either be lost to percolation into the water table or as surface runoff. Since excess surface water takes time to drain through the soil or into a basin, precipitation that falls under saturated conditions was assumed to replace any moisture lost through the next day's evapotranspiration. If the precipitation exceeded the amount of evapotranspiration in the 2-day period, the remaining amount of water left the soil.

Examples of these assumptions, which affect the supplemental water demand estimation from the recursive algorithm, are provided: if there were a constant evapotranspiration rate of $5 \mathrm{~mm} \mathrm{day}^{-1}$ and $20 \mathrm{~mm}$ of rain fell during day 1 on saturated soil, $10 \mathrm{~mm}$ was assigned to the evapotranspiration deficits (day $1+$ day 2 ) and $10 \mathrm{~mm}$ was not retained. If no additional rain fell by the end of the third day, that day's evapotranspirative demand was met by water uptake from the soil. Under these assumptions, the soil at the end of day 3 would no longer be saturated and could hold $5 \mathrm{~mm}$ of additional moisture. Another example is given: under the same 5-mm rate, $6 \mathrm{~mm}$ of rain fell during day $1,6 \mathrm{~mm}$ of rain fell in day 2 , and no additional rain fell by the end of day 3 . The soil was saturated at the start of day 1 , although no precipitation fell during the previous day. The soil remained saturated at the conclusion of day 1 with a 1-mm surplus allocated toward day 2 . At the end of day 2 , the soil remained saturated with the $1-\mathrm{mm}$ surplus from the previous day and 4 of the $6 \mathrm{~mm}$ of that day's rain covering moisture lost through evapotranspiration. By the end of day 3, the field capacity deficit is $3 \mathrm{~mm}$. 
Trends in average monthly wind speed, solar radiation, air temperature, and dewpoint temperature were calculated as was total monthly precipitation. Since regressions of daily records may include unnecessary variability and day-to-day movements are not indicative of overall climate, all trends were calculated using averaged or summed parameters over each calendar month. The summary data were then decomposed and adjusted by month to account for annual variability that could be omitted from regression coefficient slope calculations. This prevents the expected cyclical behavior of each parameter from becoming white noise in the regressions. Maintaining data on a daily resolution is, however, essential for the development of the recursive supplemental water algorithm, because monthly averages are not indicative of the short-term vulnerability of plant life to moisture stress. While it will no longer be noted in the forthcoming regression descriptions, all data and the resulting conclusions have been seasonally adjusted. Statistical modeling was conducted in RStudio (https://www.rstudio.com/), an open source, professional package used to run the $\mathrm{R}$ Project for Statistical Computing (https://www.r-project.org/).

Autoregressive time series modeling was deployed to most accurately determine historical trends. A firstorder autoregressive process assumes that an observed value in time period $t$ is linked to the observation in the previous period, $t-1$; in the following discussion each $t$ is 1 month. This autoregressive process in which $\alpha$ is a coefficient of correlation is given by

$$
z_{t}=\alpha z_{t-1}+w_{t},
$$

where $\left\{w_{t}\right\}$ is white noise with mean zero and variance $\sigma^{2}$. In a random walk process, $\alpha$ is equal to 1 . The nonstationary linkage of observation $t$ with $t-1$, however, is not necessarily attributed to an observed trend, as the value of any point in a generated random walk time series only depends on the previous value and not the point in time at which the observation occurs. While autoregressive processes may be stationary, most data series with statistically significant trends are not, as the values of their means vary with time.

Autoregressive processes of order $p>1$ contain linkages of observed values to those further in the past. The model of best fit was determined by examining the autocorrelation function of the residuals from each time series linear regression. If residuals from one or more time periods showed a statistically significant correlation, the final regression from which trends were obtained included the autoregressive process of order $p$. Each iteration increased the model order until the subsequent autocorrelation graph of residuals did not show any significant correlation. At that point, the autoregressive process was complete. Thus, model order $p$ was determined on an individual basis for each regression. This isolated each historical trend and allowed for more precise determinations of trend statistical significance. A trend was considered statistically significant if there was a $10 \%$ or less chance that the evident relationship between an observed value and the time at its occurrence was a randomly occurring pattern.

If, for example, droughts and wet periods are increasing in duration and becoming more severe, then the variance of precipitation and related parameters is time dependent. These heteroscedastic conditions will cause ordinary least squares regression coefficients to no longer be efficient even though they remain unbiased. The Breusch-Pagan Test in $R$ was used on each regression to detect whether time-varying variance was present. If there was a $90 \%$ or greater chance that the residual distance between an observation and the calculated regression value was related to time, then the regression was rerun using a robust standard errors procedure that revised the $p$ value of the coefficients. An alternative method would be to use the generalized autoregressive conditionally heteroscedastic models introduced by Engle and Granger in 1982 (Shumway and Stoffer 2016).

For subsequent regressions, including those based on output from the recursive supplemental water algorithm, the analysis period began $1 \mathrm{yr}$ later, on 1 January 1974, so the assumption of saturated soil on 1 January 1973 does not hold any influence. As described above, a specific daily value of $K_{s}$ was computed; $K_{s}$ drops below 1 whenever the reference grassy surface experiences moisture-induced stress. To produce trends in drought severity, a monthly Reimann sum approximated the area between a constant value of 1 and the actual value of $K_{s}$. In a month without moisture scarcity, the Reimann sum is equal to 0 . If soil moisture were to remain below the wilting point for an entire month, the Reimann sum would equal the number of days in that month since the height of each rectangle would be 1 unit [in this case $\left(1-K_{s, t}\right)$ is equal to 1 for all days $t$ in the month, as $K_{s}$ is equal to 0$]$.

Based on the simplified soil-precipitation interaction model used to calibrate the recursive algorithm, daily runoff totals were summed for each month and regressed. Then, the algorithm was run to estimate the water usage required for a well-watered grassy landscape. According to the literature, grass appears moisture stressed at $K_{s}$ levels below 0.7 (Rodriguez-Iturbe et al. 2001), so $25.4 \mathrm{~mm}$ (1 in.) of 


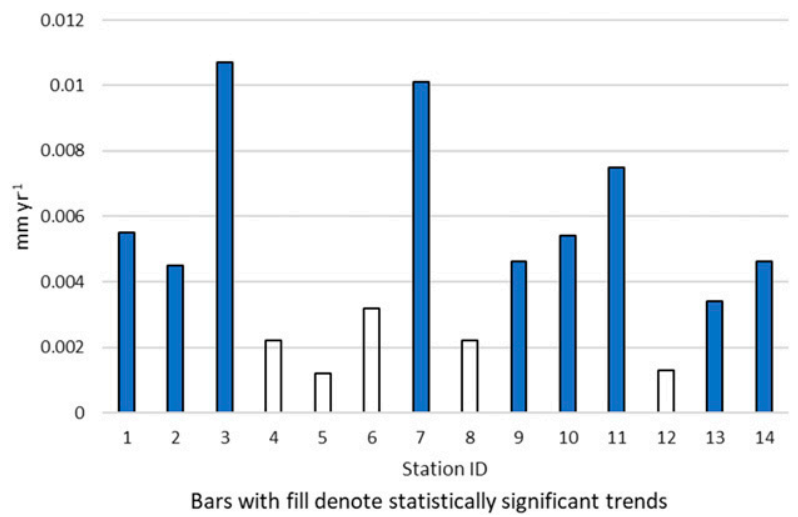

FIG. 1. Average daily $\mathrm{ET}_{0}$ trends $\left(\mathrm{mm} \mathrm{yr}^{-1}\right)$. water was introduced into the soil during the first dry day with a $K_{s}$ value below 0.7 . The amount roughly approximates one standard cycle of residential sprinkling and does not incorporate expected precipitation events beyond the conclusion of each $24-\mathrm{h}$ period. It was therefore possible for a simulated watering to occur the day before a heavy precipitation event left the soil saturated. In this case, the excess moisture was assumed to percolate through the soil or be discharged as runoff. Any sensor-based watering system would require human intervention to prevent such occurrences.

\section{Results and discussion}

All trends-the slopes of the autoregressive linear models-are reported in annual terms (the 1-yr change in value), regardless of the time scale of the original parameter. Increasing average daily reference evapotranspiration rates described in the literature were found at all observation stations, and 9 of the 14 stations have trends of statistical significance (Fig. 1). The higher rates are largely driven by increasing average daily air temperatures: all 14 locations have statistically significant positive trends. Although dewpoint temperatures are also rising, making warm air feel muggier to humans, the relative humidity at most locations is declining since air temperatures are rising at faster rates (Fig. 2). Trends in average wind speed or cloud cover also influence evapotranspiration trends to a lesser degree. Therefore, even though relative humidity has increased at stations 5 and 8 , they still exhibited an increase in reference evapotranspiration.

As reference evapotranspiration has increased, annual precipitation trends for eastern Texas are mixed, with only two locations showing a statistically significant correlation between time and total accumulated monthly precipitation. While both exhibited negative annual trends, six other sites did show insignificant increases. Figure 3

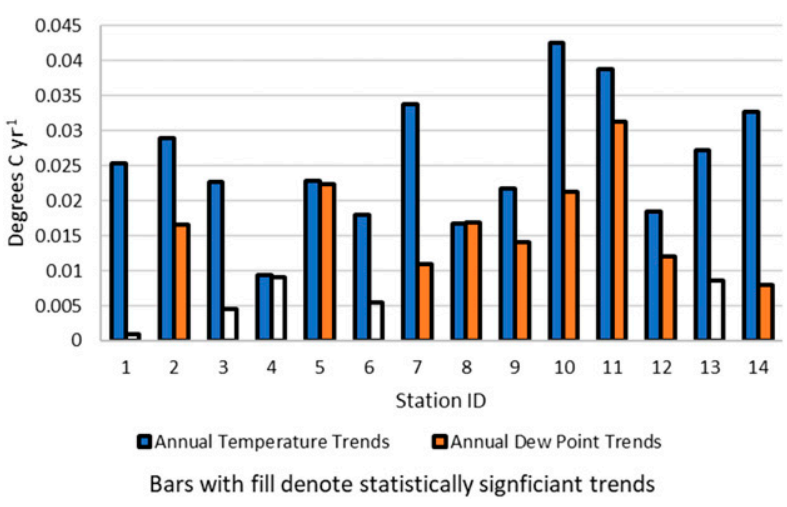

FIG. 2. Average daily air temperature and dewpoint temperature trends $\left({ }^{\circ} \mathrm{C} \mathrm{yr}^{-1}\right)$.

displays annual trends in accumulated monthly precipitation with annual $\mathrm{ET}_{0}$ trends on the same time scale. The results show increasing aridity in the region, as higher evaporation rates generally are not being offset by additional rainfall. For context, average annual precipitation and reference evapotranspiration are also shown for 1973 through 2017 (Fig. 4).

Even in the wettest regions in the east, considerable amounts of water are needed to preserve the wellwatered grass assumed for reference evapotranspiration calculations, as entrenched droughts and wet patterns cause time-related disparities between water availability and evapotranspirative demand. Trends in the average amount of water falling each month that cannot be absorbed into saturated soils are shown in Fig. 5. Figure 6 displays the average proportion of annual precipitation that becomes runoff or infiltration water at each location. While this precipitation may not be used to directly satiate the demands of vegetation in the recursive algorithm, runoff can be captured and stored in reservoirs while percolation can recharge aquifers. Potential utilization of this water depends on

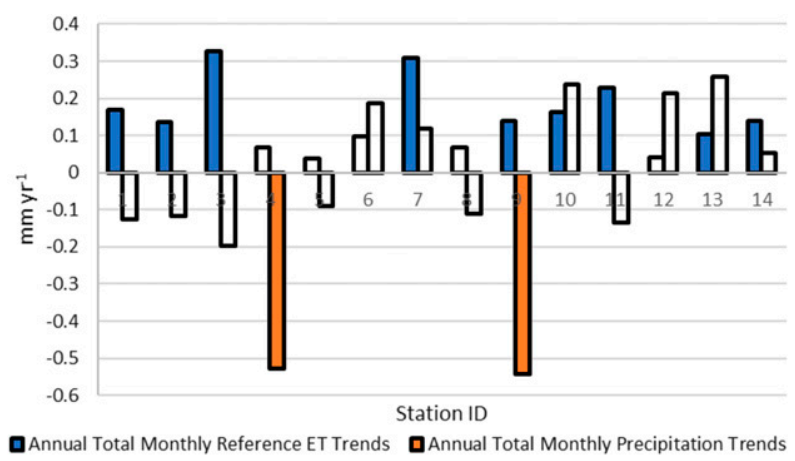

Bars with fill denote statistically signficiant trends

FIG. 3. Average accumulated monthly $\mathrm{ET}_{0}$ and precipitation trends $\left(\mathrm{mm} \mathrm{yr}^{-1}\right)$. 


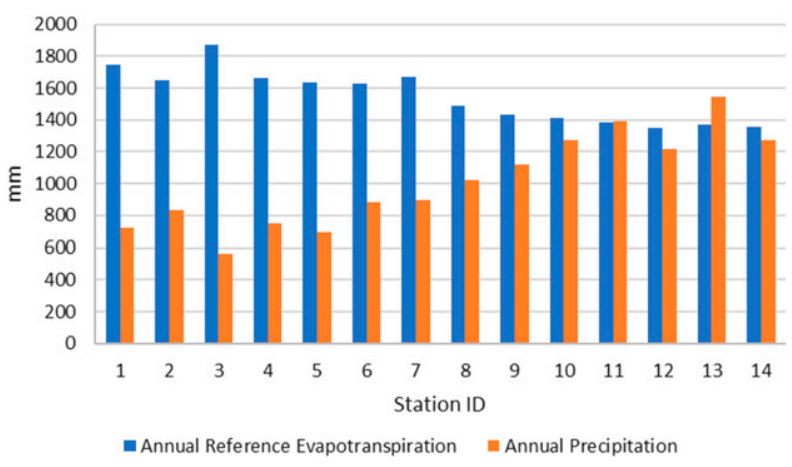

FIG. 4. Average annual $\mathrm{ET}_{0}$ and precipitation (mm).

many factors that are excluded from this analysis. The use of adjusted average monthly data should not be used in effective infrastructure planning that must consider highly variable water cycles.

Deepening drought patterns are exhibited in the trends associated with the monthly totals of accumulated daily $K_{s}$ values below 1 , an approximation of drought severity using Reimann sums. Described earlier, the measures are unitless, but higher values equate to greater degrees of moisture stress. The wettest observation location, station 13, has the lowest 1974-2017 average value of 5.7, while station 5 has an average value of 20.6, indicating the highest level of monthly moisture deficits (a hypothetical location with an unlimited supply of moisture would be at 0 while a location permanently at wilting point would be at 30.4). Even though all but one of the observation sites had positive trends, only two were statistically significant.

Trends were positive for the recursive supplemental watering algorithm in all locations, with 7 of 14 locations showing statistically significant increases in the amount of water required to prevent grass from browning (Fig. 6). From 1974 to 2017, station 11 required the fewest seasonally adjusted waterings, translating to $23.1 \mathrm{~mm}$ of

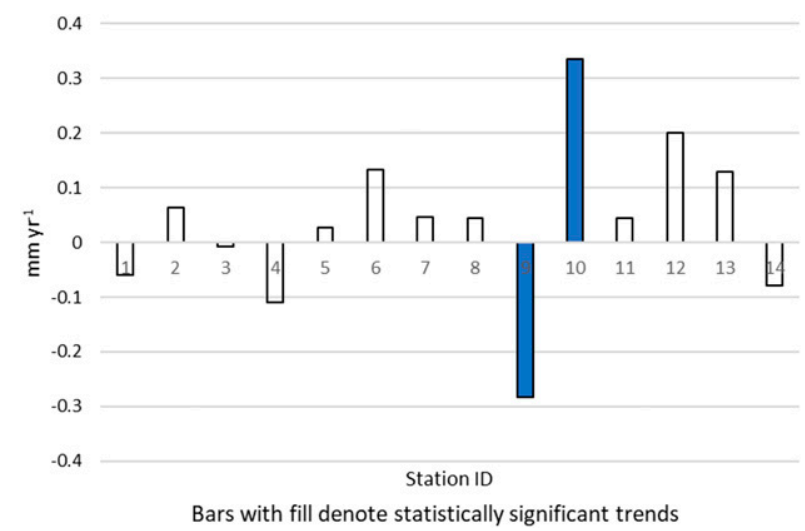

FIG. 5. Average accumulated monthly runoff trends $\left(\mathrm{mm} \mathrm{yr}^{-1}\right)$.

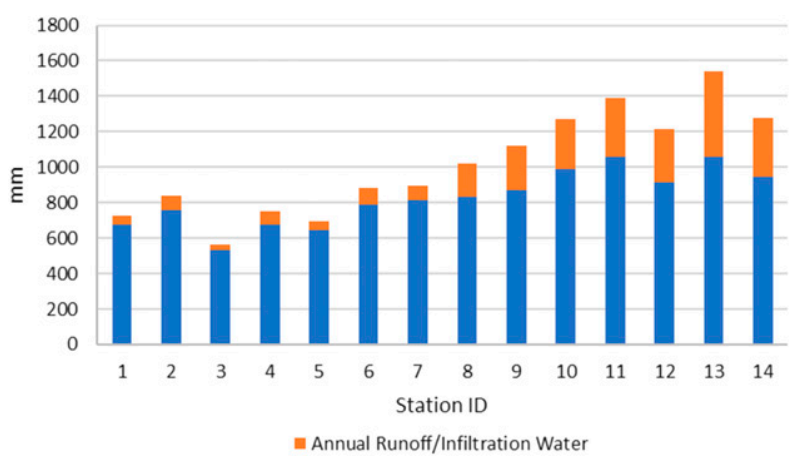

FIG. 6. Average annual runoff/infiltration water as a proportion of average annual precipitation $(\mathrm{mm})$.

additional water per month, or $277.3 \mathrm{~mm} \mathrm{yr}^{-1}$ (the station receives $1392 \mathrm{~mm}$ of precipitation in an average year). The greatest number of waterings was required at station 3, which had $90.1 \mathrm{~mm}$ of monthly demand. Over the course of an average year, that station would require $1082 \mathrm{~mm}$ of supplemental water to preserve the reference surface in a well-watered state; this is $192.2 \%$ of the average precipitation that the station receives.

Using the monthly trends from the recursive algorithm output shown in Fig. 7, average annual water demand in each location was calculated for the first and final year of the analysis period. The resulting amounts are not historical values of usage in these years, but rather the average amount of water that would be needed to preserve well-watered grass during normal conditions. Figure 8 shows the growing water usage requirements in all 14 observation sites. ${ }^{1}$ Station 3 has the largest trend, equating to an additional $214.9 \mathrm{~mm}$ of annual expected demand in 2017 relative to 1974. Applying this amount of additional moisture to 1 ha of land requires 2.1 million liters (586000 gallons) of water. The second-largest trend, occurring at station 9, would require an additional 1.4 million liters in an average year occurring at the end of the analysis period. Thus, preserving vegetation in the same well-watered state across eastern Texas will require more frequent waterings and raise overall consumption, assuming plant life is not replaced with drought-tolerant species.

On a qualitative level, the increases in demand make wetter cities that had been less prone to drought similar in climate to drier locations 44 years earlier. When considering a lawn watering schedule, a resident of Dallas, Texas, can expect current conditions to mimic those of

\footnotetext{
${ }^{1}$ Observation station 12 has a negligible trend, as shown in Fig. 7. Although positive, the trend is so small that a demand comparison between the two periods is essentially flat.
} 


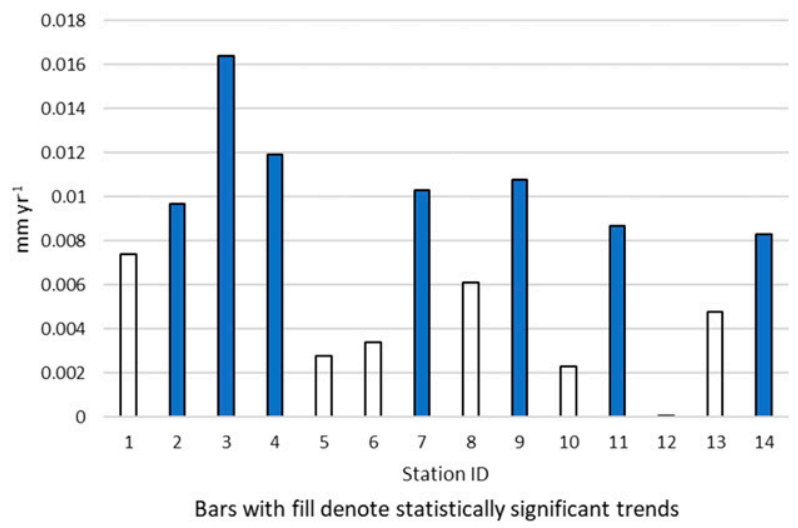

FIG. 7. Average accumulated monthly required watering trends $\left(\mathrm{mm} \mathrm{yr}^{-1}\right)$.

Brownsville, Texas, in 1974. Watered grassy surfaces in Port Arthur, Texas, now consume as much water as those near Houston Intercontinental Airport 44 years earlier in an average year. Within Houston, watered grass at Hobby Airport requires more supplemental water, on average, than the same grass at Intercontinental Airport did at the beginning of the period, despite the location of Hobby Airport in one of the wettest parts of the metropolitan area.

\section{Conclusions}

Although the existing body of literature has noted more frequent extreme precipitation events, deeper droughts, and higher rates of evapotranspiration for the southern plains-all trends that are projected to continue-this analysis used daily historical climate data at 13 locations in eastern Texas and 1 near its border in Louisiana to relate climatic changes to municipal water usage associated with landscape preservation through the creation of a recursive algorithm.

Deploying the Penman-Monteith equation, climate records were used in reference evapotranspiration estimations. Precipitation data and site-specific soil characteristics enabled the modeling of soil moisture availability. Under water-scarce conditions, reference evapotranspiration was curtailed by a vegetation stress coefficient. Using adjusted evapotranspiration estimates is imperative for the operation of the recursive supplemental water algorithm. While the algorithm output estimates optimal watering practices, the amount of water applied to landscaping is often restricted in dry periods, so overall usage may fall at the expense of sensitive plant life. Moreover, there are a wide variety of watering methods that depend on socioeconomic factors, the type of plantings, and local policies. The algorithm can also be used to analyze resulting landscape stress increases under proposed restricted watering regulations or guidelines.

Temperatures have unequivocally risen at every station over the period from 1973 through 2017. Dewpoint temperatures have not shown increases that are as robust, dropping relative humidity and increasing reference evapotranspiration. Without overall positive trends in the amount of precipitation, the area is becoming more arid and the amount of water needed to maintain a plot of green grass, as estimated by the recursive tool, is higher today than it was just over 40 years ago. Irrigated agriculture is excluded from the discussion, but increasing dryness will lead to

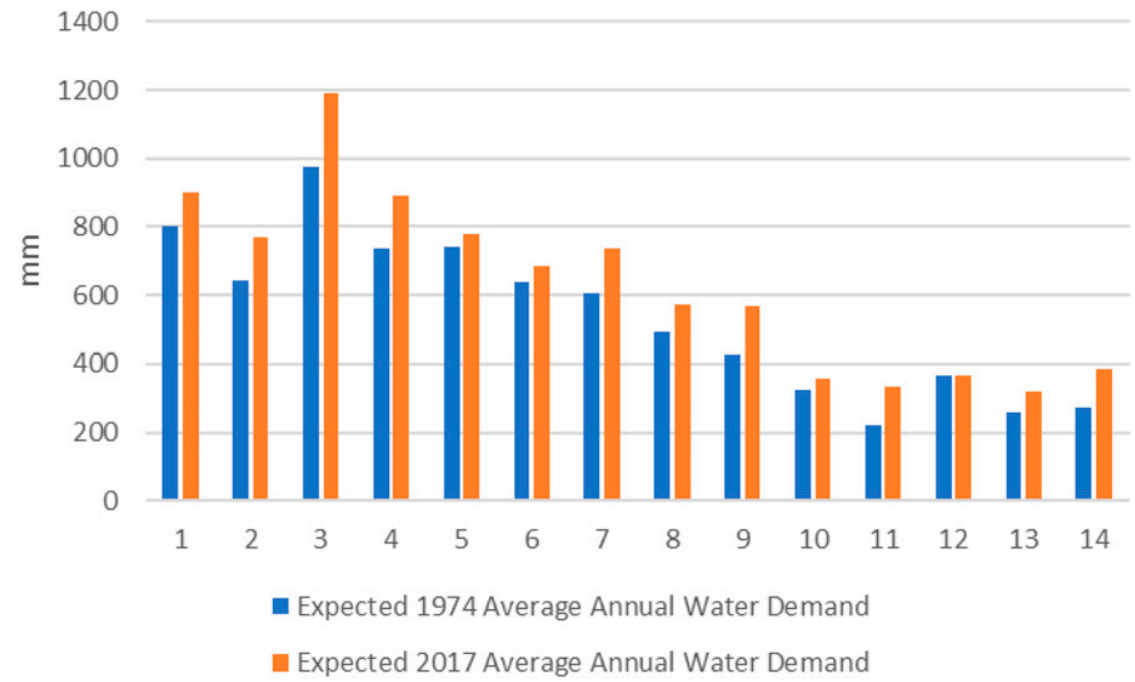

FIG. 8. Average annual expected water demand for a well-watered grassy surface $(\mathrm{mm})$ for two different years. 
more highly stressed crops unless drought tolerance is increased or more water is applied to cropland.

Although this study uses quality-controlled data, there are publicly available applications from the U.S. government that provide accurate estimates of many of the calculated parameters (https://giovanni.gsfc.nasa. gov/giovanni/). These applications allow users to visualize data blended across observation sites and deploy time series analysis techniques to determine multiple correlations. Even though greater accuracy may be possible using packaged sets relative to the method described here for parameter analysis, such applications preclude the development of a recursive algorithm in which each watering, decided by data from previous days, affects subsequent conditions and demand. Estimates obtained by co two or more static datasets over time lack the real-time decision-making capability of the algorithm. Its structure is basic, allowing accessibility and versatility for modifications and enhancements.

Results should be not be interpreted as an assertion that years in which above average precipitation falls are becoming less common or drier; the last year of this reference period was the wettest on record for many locations in Texas. They instead indicate increasing stress on vegetation in an average year and that growing the same plants in the same location now requires, on average, more water.

In this analysis, total daily precipitation may penetrate the soil as long as the ground remains unsaturated. This presumes $50 \mathrm{~mm}$ of rain falling over a 24 -h period has the same absorption rate as $50 \mathrm{~mm}$ of rain falling in less than an hour. The positive trends noted in the literature for extremely heavy precipitation events occurring within short timeframes would augment the positive supplemental watering trends exhibited since higher amounts of water would run off the surface. The impacts would be location-specific since water penetration rates differ by soil type and topography.

As temperatures continue to rise without larger increases in precipitation, eastern Texas will become more arid and water demand to maintain landscaping will increase. Confidence in future temperature rise is high, but projected precipitation amounts are less certain (Hayhoe et al. 2018). Heavy sporadic events, coinciding with drought, are expected to supplant some of the steady, soaking rainfalls of the past. It remains to be seen whether the multiyear drought of the 1950s will be repeated in the near future or if another calendar year will be as costly as 2011, but averages are inching toward a drier future that requires more supplemental moisture, reducing the contrast between normal conditions and impactful drought.
Acknowledgments. Der-Chen Chang's research is partially supported by a National Science Foundation grant (DMS-1408839) and the McDevitt Endowment Fund at Georgetown University. The authors also thank their colleagues, especially Ali Arab of Georgetown University, for guidance on time series data analysis.

\section{REFERENCES}

AghaKouchak, A., D. Easterling, K. Hsu, S. Schubert, S. Sorooshian, 2013: Extremes in a Changing Climate: Detection, Analysis, and Uncertainty. Springer, $422 \mathrm{pp}$.

Burian, S., and J. Shepherd, 2005: Effect of urbanization on the diurnal rainfall pattern in Houston. Hydrol. Processes, 19, 1089-1103, https://doi.org/10.1002/hyp.5647.

Easterling, D., and Coauthors, 2017: Precipitation change in the United States. Climate Science Special Report: Fourth National Climate Assessment, Vol. I, D. J. Wuebbels et al., Eds., U.S. Global Change Research Program, 185-206, https://science2017. globalchange.gov/downloads/CSSR_Ch7_Precipitation.pdf.

Ferguson, B., 1987: Water conservation methods in urban landscape irrigation: an exploratory overview. J. Amer. Water Resour. Assoc., 23, 147-152, https://doi.org/10.1111/j.1752-1688.1987.tb00794.x.

Ficklin, D., J. T. Maxwell, S. L. Letsinger, and H. Gholizadeh, 2015: A climate deconstruction of recent drought trends in the United States. Environ. Res. Lett., 10, 044009, https://doi.org/ 10.1088/1748-9326/10/4/044009.

Fritsch, R., R. J. Kane, and C. R. Chelius, 1986: The contribution of mesoscale convective weather systems to the warm-season precipitation in the United States. J. Climate Appl. Meteor., 25, 1333-1345, https://doi.org/10.1175/1520-0450(1986)025<1333: TCOMCW $>2.0 . \mathrm{CO} ; 2$.

Hayhoe, K., and Coauthors, 2018: Our changing climate. Impacts, Risks, and Adaption in the United States: Fourth National Climate Assessment, Vol. II, D. R. Reidmiller et al., Eds., U.S. Global Change Research Program, 72-144, https:// nca2018.globalchange.gov/downloads/NCA4_Ch02_ChangingClimate_Full.pdf.

Henry, T., 2013: House passes big water bill. Texas Tribune, accessed 11 May 2019, https://www.texastribune.org/2013/03/27/ texas-house-passes-water-bill.

Jensen, M. E., and R. G. Allen, Eds., 2016: Evaporation, Evapotranspiration, and Irrigation Water Requirements. 2nd ed. ASCE, https://doi.org/10.1061/9780784414057.

Kloesel, K., and Coauthors, 2018: Southern Great Plains. Impacts, Risks, and Adaption in the United States: Fourth National Climate Assessment, Vol. II, D. R. Reidmiller et al., Eds., U.S. Global Change Research Program, 987-1035, https:// nca2018.globalchange.gov/downloads/NCA4_Ch23_SouthernGreat-Plains_Full.pdf.

Kramer, R., and Coauthors, 2015: Evapotranspiration trends over the eastern United States during the 20th century. Hydrology, 2, 93-111, https://doi.org/10.3390/hydrology2020093.

Lall, U., and Coauthors, 2018: Water. Impacts, Risks, and Adaption in the United States: Fourth National Climate Assessment, Vol. II, D. R. Reidmiller et al., Eds., U.S. Global Change Research Program, 145-173.

Long, D., B. R. Scanlon, L. Longuevergne, A. Y. Sun, D. N. Fernando, and H. Save, 2013: GRACE satellite monitoring of large depletion in water storage in response to the 2011 drought in Texas. Geophys. Res. Lett., 40, 3395-3401, https:// doi.org/10.1002/grl.50655. 
McGregor, K., 2015: Comparison of the recent drought in Texas to the drought of record using reanalysis modeling. Pap. Appl. Geogr., 1, 34-42, https://doi.org/10.1080/23754931.2015.1009295.

National Weather Service Houston, 2019: Houston's Annual Top 10 List. NWS/Galveston, TX, accessed 10 February 2019, https://www.weather.gov/hgx/climate_iah_top10_annual.

Nielson-Gammon, J., 2012: The 2011 Texas drought. Tex. Water J., 3 (1), 59-95.

Prein, A., G. J. Holland, R. M. Rasmussen, M. P. Clark, and M. R. Tye, 2016: Running dry: The U.S. Southwest's drift into a drier climate state. Geophys. Res. Lett., 43, 1272-1279, https:// doi.org/10.1002/2015GL066727.

Rodriguez-Iturbe, I., A. Porporato, F. Laio, and L. Ridolfi, 2001: Plants in water-controlled ecosystems: Active role in hydrologic processes and response to water stress: I. Scope and general outline. Adv. Water Resour., 24, 695-705, https:// doi.org/10.1016/S0309-1708(01)00004-5.

Ryu, J., and K. Hayhoe, 2017: Observed and CMIP5 modeled influence of large-scale circulation on summer precipitation and drought in the south-central United States. Climate Dyn., 49, 4293-4310, https://doi.org/10.1007/ s00382-017-3534-z.

Schmandt, J., G. North, and J. Clarkson, 2011: The Impact of Global Warming on Texas. University of Texas Press, 328 pp.

Seager, R., L. Goddard, J. Nakamura, N. Henderson, and D. E. Lee, 2014: Dynamical causes of the 2010/11 Texas-northern Mexico drought. J. Hydrometeor., 15, 39-68, https://doi.org/ 10.1175/JHM-D-13-024.1.
— N. Lis, J. Feldman, M. Ting, A. P. Williams, J. Nakamura, H. Liu, and N. Henderson, 2018: Whither the 100th meridian? The once and future physical and human geography of America's arid-humid divide. Part I: The story so far. Earth Interact, 22, https://doi.org/10.1175/EI-D-17-0011.1.

Shumway, R., and D. Stoffer, 2016: Time Series Analysis and Its Applications with $R$ Examples. 4th ed. Springer, $558 \mathrm{pp}$.

Svoboda, M., and Coauthors, 2002: The Drought Monitor. Bull. Amer. Meteor. Soc., 83, 1181-1190, https://doi.org/10.1175/ 1520-0477-83.8.1181.

Texas Water Development Board, 2017: State water plan. State of Texas Doc., 134 pp.

Wang, G., W. Cai, B. Gan, L. Wu, A. Santoso, X. Lin, Z. Chen, and M. J. McPhaden, 2017: Continued increase of extreme El Niño frequency long after $1.5^{\circ} \mathrm{C}$ warming stabilization. Nat. Climate Change, 7, 568-572, https://doi.org/10.1038/nclimate3351.

Wang, H., R. Fu, A. Kumar, and W. Li, 2010: Intensification of summer rainfall variability in the southeastern United States during recent decades. J. Hydrometeor., 11, 1007-1018, https:// doi.org/10.1175/2010JHM1229.1.

Wright, J., 1993: Nongrowing season ET from irrigated fields. Management of Irrigation and Drainage Systems: Integrated Perspectives, ASCE, 1005-1014.

Zontarelli, L., M. D. Dukes, C. C. Romero, K. W. Migliaccio, and K. T. Morgan, 2010: Step by step calculation of the PenmanMonteith evapotranspiration (FAO-56 method). University of Florida Institute of Food and Agricultural Sciences Doc. AE459, 10 pp., http://edis.ifas.ufl.edu/pdffiles/ae/ae45900.pdf. 